\title{
Statement on Health Rights in the New Constitution
}

\author{
Korea Health Rights Working Group
}

As detailed discussions on constitutional amendments continue to progress, the content that will be included in the new Constitution is being publicized. However, the current discussions on the Constitution focus on power restructuring, and do not fully reflect the demands of members of society for basic human rights.

Healthcare and public health professionals who belong to the Korean Society for Preventive Medicine and other related societies in the field of public health are deeply concerned that the current health inequalities in Korea can seriously threaten the sustainability and human rights of our society. We strongly argue that the Constitution should be amended in the direction of strengthening the state's responsibility for health, which is weakly defined in the present Constitution.

According to Article 36 (3) of the Constitution of Korea, "the health of all citizens shall be protected by the State." However, these provisions do not adequately reflect everyone's right to the enjoyment of the highest attainable standard of physical and mental health specified in Article 12 of the International Covenant on Economic, Social and Cultural Rights of the United Nations. As a result, the Korean government still fails to take full responsibility for essential healthcare, and many people suffer from a heavy financial burden due to medical expenses not covered by the National Health Insurance program. The government has implemented several important healthcare policies, such as expanding service coverage in the $\mathrm{Na}$ tional Health Insurance program and establishing the national dementia program as part of Moon Care. Since the current Constitution does not clearly specify the state's responsibility

This is an Open Access article distributed under the terms of the Creative Commons Attribution Non-Commercial License (http://creativecommons.org/licenses/by$\mathrm{nc} / 4.0 /$ ) which permits unrestricted non-commercial use, distribution, and reproduction in any medium, provided the original work is properly cited. for health, it is possible that the state will pass on responsibility for health to the individual.

As members of society in Korea, we must all have the right to equally enjoy the highest level of health that can be achieved in this society. In this context, members of society should be defined as including migrant workers, international students, and refugees, as well as Korean citizens. Everyone in our society must have equal rights to health. The scope of health rights is not limited to the accessibility or cost of healthcare. In order to guarantee health rights, an equal and comprehensive approach should be taken to the right to health so that gaps or discrimination in health caused by non-medical determinants, such as socioeconomic and environmental factors, can be resolved.

The new Constitution should define the responsibility of the state for the health rights that are already universally realized in Western welfare states. The constitutional right to health will be a cornerstone in promoting the health of all members of society and achieving universal health coverage. Such a reform would open up the possibility of ensuring equal healthcare access among geographically, socially, economically, or culturally vulnerable populations; of meeting the needs of all members of society; and of reducing health disparities.

The state should also be responsible for the loss of income from sickness. Health insurance and industrial accident compensation insurance should be equal in terms of rights. Regardless of the origin of the disease or injury, the state should equally guarantee healthcare costs and the loss of income, so that members of the society can return to home, work, and society in a healthy state. Furthermore, the state's responsibility for the right to health must go beyond guaranteeing healthcare and loss of income. A strong national commitment is needed to properly manage the socioeconomic, cultural, 
and environmental factors that affect health disparities. The state should actively take preventive actions to reduce gaps in health determinants such as employment, education, housing, nutrition, drinking water, atmosphere, environment, and safety. Professional organizations for public health such as the Korean Society for Preventive Medicine strongly advocate that the following provisions should be included in the amended Constitution to promote sustainable growth, make all members of society healthy, and become a more people-centered society.

First, the amended Constitution should define the active duty of the state regarding health rights.

Second, the new Constitution should expand the subject of health rights from Korean citizens to all members of our society, including migrant workers.

Third, the revised Constitution should extend the range of health rights to include non-medical determinants of health in order to resolve health inequalities in a prompt manner.
The Korean Society for Preventive Medicine and other professional organizations for public health solemnly declare that the Constitution should be amended in this direction.

\section{SUPPLEMENTAL MATERIALS}

Korean version is available at https://www.jpmph.org/.

\section{ACKNOWLEDGEMENTS}

Endorsement by The Academy of Critical Health Policy; The Korean Society of Global Health; The Korean Society for Preventive Medicine; The Korean Society for Patient Safety; The Korean Society for Rural Medicine and Community Health; The Korea Society of Health Policy and Administration; The Korean Society of Epidemiology; The Korean Academy of Primary Health Care; The Korean Society of Occupational Stress. 